\title{
SPD in illumination system of HV air insulated substation
}

\author{
Anton Kosorukov ${ }^{1}$, Pavel Karpov ${ }^{2}$, Nataliya Kutuzova ${ }^{3}$, Svetlana Pashicheva ${ }^{4, *}$, and Vasiliy \\ Titkov $^{4}$ \\ 1 JSC «Lenhydroproect», Ispytateley Street, 22, St. Petersburg, 197227, Russia \\ ${ }^{2}$ LLC «EMC-project», Obruchevyh Street, 5A, St. Petersburg, 194064, Russia \\ ${ }^{3}$ JSC «NPO «Streamer», Nevsky Prospect, 147, St. Petersburg, 191024, Russia \\ ${ }^{4}$ Peter the Great St.Petersburg Polytechnic University, Polytechnicheskaya Street, 29, St. Petersburg, \\ 195251, Russia
}

\begin{abstract}
The article discusses the distribution of the lightning current between communications of the object as the main aspect determining surge protective devices (SPDs) parameters for applying in substation's low voltage networks. Wireframe model was designed to compute fieldcircuit model of earthing device (ED) and define the element potentials and currents using circuit analysis methods. Transients were calculated using operator method. Results of calculation and measurements of the lightning current's distribution in ED and cables in illumination network of air insulated substation presented. Experimental study results obtained in training ground PJSC «Lenenergo», one of the largest electric power distribution company in Russia. Case of lightning strike in the floodlight mast combined $\mathrm{c}$ with lightning rod in $110 \mathrm{kV}$ air insulated substation was studied. Requirements for the parameter "impulse discharge current amplitude" SPD defined. Described general approaches to the illumination network's lightning surge protection on air insulated substation.
\end{abstract}

\section{Introduction}

Lightning overvoltages perform the most significant impact on requirements for ensuring EMC of at high-voltage substations up to $220 \mathrm{kV}$. Other interference sources, including the high-voltage network, have significantly lower energy.

Due to the relatively small dimensions of the objects, cable lines (CL) of substation's low voltage systems are located close to the elements of the lightning protection system. However, air insulated substations are not compact objects, being compared with lower voltage class indoor switchgears or with other infrastructural facilities, for example, mobile communication station, etc. In described conditions the routs of CL are not restricted by shielded volume (in terms of IEC 62305 standard [1] - within one lightning protection zone (LPZ)).

One of the most effective means of limiting overvoltage is the hardware protection of equipment using SPD. SPD is an additional element of the low voltage network that can

${ }^{*}$ Corresponding author: pashicheva.sv@gmail.com 
reduce reliability. Incorrect selection of SPD parameters and its installation location can lead to damage to protected equipment by lightning current [2-6].

SPDs class I placed in LPZ 0 and 1 must be capable of conducting partial lightning currents of $10 / 350 \mu$ s wave form without being destroyed. The main parameter determining the SPD class I applicability is an impulse discharge current. This parameter has an influence on the device's price. Standardized impulse discharge current values for class I test defined in [7].

Impulse current evaluation methods described in IEC 62305 and 61643 standards [1, 8 ], do not consider the design characteristics of the power facilities such as developed grounding network and the absence of low-voltage networks extending beyond the ED. Parameters of other protected objects also aren't considered in terms of lightning current distribution. The aforecited problems may be the cause of incorrect selection of SPDs parameters at the design stage.

It has to be noted, that impulse discharge current parameters recommended to test SPD do not consider data published in [9]. The main concern is the lack of consideration for the multi-component nature of lightning discharges.

The purpose of the measurements and calculations presented in the article is to evaluate the distributed currents in conductors on air insulated substation.

The illumination system of HV air insulated substation is one of the most exposed to conductive surges due to the placing of the lightning equipment directly on tower with lightning rods. It seems appropriate to use SPDs for this system protection. Placing other equipment on structures with lightning rods is less common, and the topology of the power supply networks of such equipment is more complicated. The certainty in the mutual position of the interference source and the cable network of the illumination system allows us to create the required calculation model. An analysis of the processes of distribution lightning current was carried out for the lighting equipment of the floodlight masts located in air insulated substation.

\section{Model and parameters}

Wireframe model of $110 \mathrm{kV}$ air insulated substation (Fig.1) was designed to compute the field-circuit model of $\operatorname{ED}[13,15]$ and to demonstrate the impact of substation design on the part of the lightning current distributed in the conductors of the illumination system. The results obtained using FDTD method was excluded due to the inconsiderable difference and the prolonged computation [10-12]. The software program ZYM (AutoCAD application) also was used for electromagnetic fields and transients calculations [14]. 


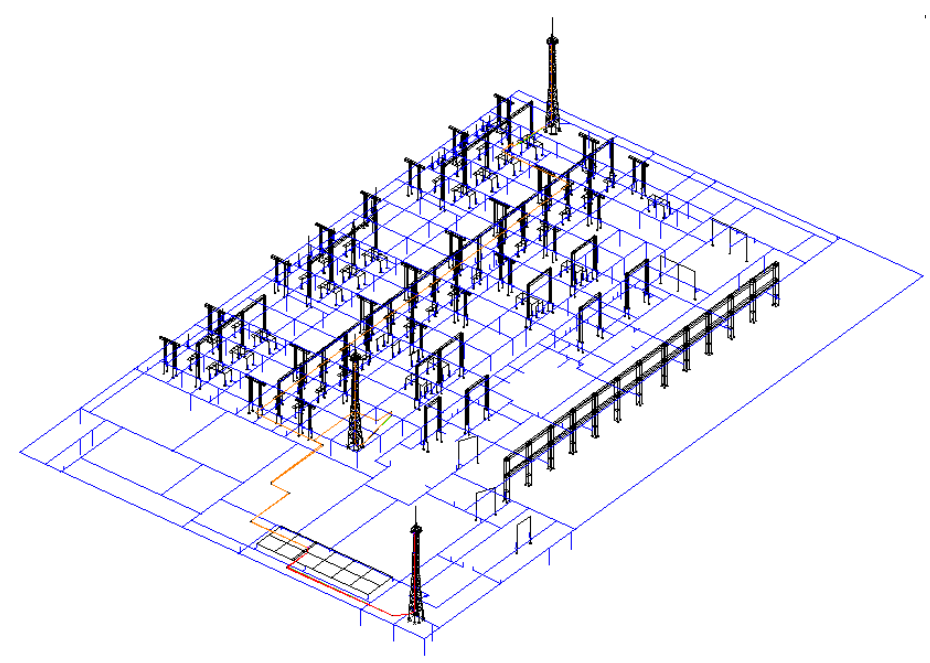

Fig. 1. $110 \mathrm{kV}$ air insulated substation calculation model.

Overvoltages evaluation was performed in order to justify the necessity of the use of SPD in the substation illumination system. The impact of the CL's length and the presence of metal pipe in a CL construction were considered. The floodlight mast had multiple connections through the ED to the illumination control system earthing point placed in the building of the substation. An assessment of overvoltage and currents in CL was carried out with an impulse with a waveform 10/350 $\mu$ s and amplitude of $100 \mathrm{kA}$, which is considered a simulation of lightning current [1].

Lightning strikes in floodlight masts combined c with lightning rod were simulated. Cable length between illumination control switchboard and masts is $50 \mathrm{~m}$ and $220 \mathrm{~m}$. Different cable lying conditions were considered: shielded CL in metal pipe, not shielded CL in metal pipe, not shielded CL without pipe. Parameters of a single-phase cable were used.

The PE conductor was connected to the illumination distribution board located on the mast, to the floodlight and to the illumination control system earthing point. The capacity of the power supply of the floodlight is taken equal to $100 \mathrm{nF}$. The cable from the side of the substation control house is disconnected, the phase conductor is broken, the neutral conductor is grounded.

Computation results of lightning current distribution in modeled illumination network also were carried out with an impulse with a waveform 10/350 $\mu$ s and amplitude of $100 \mathrm{kA}$. In calculations weren't considered the presence of a shield at the CL and the resistance of the SPD. All conductors of CL were grounded.

\section{Computation results discussion}

Obtained results of overvoltages values for a floodlight mast placed $50 \mathrm{~m}$ (via a cable line) away from the illumination control board in substation control house are summarized in Table 1.

As seen, the overvoltage level is determined mainly by the type of cable lying conditions. The pipe and the shield due to capacitive and inductive coupling with cable conductors significantly reduce the level of overvoltage. It corresponds to the theoretical concepts. 
Table 1. Overvoltage values for different cable lying conditions.

\begin{tabular}{|c|c|c|c|c|c|c|c|c|c|}
\hline \multirow{3}{*}{$\begin{array}{c}\text { Cable } \\
\text { lying } \\
\text { condition } \\
\mathrm{s}\end{array}$} & \multirow{3}{*}{$\begin{array}{l}\text { Soil } \\
\text { resistivity } \rho, \\
\Omega \cdot \mathrm{m}\end{array}$} & \multirow{3}{*}{$\begin{array}{l}\text { Earthing resistance at } \\
\text { the main frequency } \\
\text { of exposure } z, \Omega\end{array}$} & \multicolumn{7}{|c|}{$\mathrm{U}, \mathrm{kV}$} \\
\hline & & & \multicolumn{3}{|c|}{ floodlight } & \multicolumn{3}{|c|}{$\begin{array}{l}\text { distribution board } \\
\text { on mast }\end{array}$} & \multirow{2}{*}{ 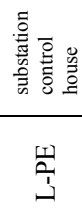 } \\
\hline & & & 望 & 䆓 & 桨 & 䆓 & 聜 & $z_{i}$ & \\
\hline \multirow{5}{*}{ 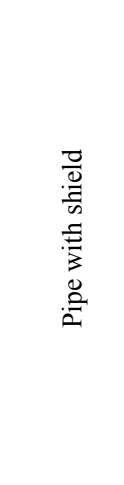 } & 100 & 5.4 & $\hat{\sigma}$ & $\stackrel{\hat{n}}{i}$ & $\stackrel{0}{\circ}$ & 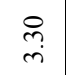 & $\underset{\sim}{\stackrel{J}{\sharp}}$ & $\frac{n}{0}$ & \multirow{5}{*}{$<0.2$} \\
\hline & 250 & 6.5 & $\stackrel{\overrightarrow{+}}{\partial}$ & 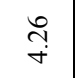 & $\stackrel{7}{0}$ & $\stackrel{+}{\stackrel{i}{n}}$ & $\vec{\sigma}$ & $\stackrel{5}{0}$ & \\
\hline & 500 & 7.8 & $\hat{m}$ & $\stackrel{\tilde{f}}{\sim}$ & $\stackrel{\infty}{\circ}$ & $\underset{+}{\tilde{+}}$ & $\stackrel{\vartheta}{\vec{f}}$ & $\stackrel{\infty}{\stackrel{0}{0}}$ & \\
\hline & 750 & 8.8 & $\stackrel{n}{\sim}$ & $\begin{array}{l}\mathfrak{n} \\
\dot{r}\end{array}$ & $\stackrel{\infty}{\longrightarrow}$ & $\stackrel{\infty}{\underset{+}{+}}$ & $\stackrel{\mathscr{m}}{+}$ & $\frac{9}{0}$ & \\
\hline & 1000 & 9.6 & $\stackrel{\beta}{+}$ & $\stackrel{\Re}{\stackrel{r}{r}}$ & $\stackrel{\infty}{\circ}$ & 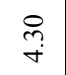 & $\underset{+}{\stackrel{f}{*}}$ & $\frac{9}{0}$ & \\
\hline \multirow{5}{*}{$\stackrel{0}{:}$} & 100 & 5.4 & $\stackrel{0}{\dddot{n}}$ & $\underset{\sim}{\infty}$ & \begin{tabular}{l}
$\infty$ \\
\multirow{0}{0}{}
\end{tabular} & જે & $\hat{N}$ & $\tilde{\overbrace{}}$ & 1.01 \\
\hline & 250 & 6.5 & $\stackrel{n}{n}$ & $\stackrel{\circ}{\circ}$ & Iี. & $\stackrel{\Xi}{\circ}$ & ֶี & $\tilde{n}$ & 1.69 \\
\hline & 500 & 7.8 & $\stackrel{n}{n}$ & $\stackrel{\infty}{\circ}$ & $\bar{n}$ & $\stackrel{m}{\stackrel{m}{c}}$ & $\stackrel{\stackrel{q}{i}}{i}$ & $\begin{array}{l}\text { to } \\
\stackrel{0}{\circ}\end{array}$ & 2.14 \\
\hline & 750 & 8.8 & $\stackrel{n}{n}$ & $\begin{array}{l}\infty \\
\stackrel{\infty}{\Xi} \\
\dot{\Xi}\end{array}$ & $n$ & $\begin{array}{l}0 \\
\stackrel{2}{n}\end{array}$ & $\stackrel{\stackrel{q}{+}}{\stackrel{m}{\rightarrow}}$ & oे & 2.37 \\
\hline & 1000 & 9.6 & $\stackrel{ \pm}{ \pm}$ & $\stackrel{尺}{\stackrel{+}{ \pm}}$ & $n$ & $\stackrel{\vec{\vartheta}}{\vec{g}}$ & $\begin{array}{l}\vec{\partial} \\
\dot{\Xi}\end{array}$ & $\stackrel{2}{0}$ & 2.51 \\
\hline \multirow{5}{*}{ 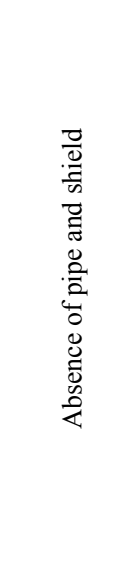 } & 100 & 5.6 & ๗ี & $\begin{array}{l}\stackrel{8}{n} \\
+0\end{array}$ & $\bar{m}$ & 年 & $\begin{array}{l}8 \\
\text { ڤे } \\
\text { in }\end{array}$ & $\stackrel{m}{m}$ & 7.37 \\
\hline & 250 & 6.8 & $\begin{array}{c}\hat{n} \\
\dot{n} \\
\infty\end{array}$ & 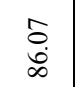 & ڤె. & 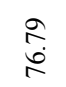 & $\stackrel{\substack{n \\
\stackrel{n}{n}}}{n}$ & $\stackrel{\infty}{+}$ & 10.18 \\
\hline & 500 & 8.1 & $\begin{array}{l}\text { ర్ర } \\
\stackrel{2}{\alpha}\end{array}$ & $\frac{\pi}{2}$ & $m_{0}^{m}$ & $\begin{array}{l}\vec{\sigma} \\
\stackrel{\infty}{\infty}\end{array}$ & $\begin{array}{l}\stackrel{+}{1} \\
\stackrel{2}{\Omega}\end{array}$ & $\stackrel{n}{n}$ & 12.15 \\
\hline & 750 & 9.1 & ڤે & $\hat{\tilde{\varepsilon}}$ & $\hat{o}$ & \begin{tabular}{l}
$\infty$ \\
\multirow{n}{n}{} \\
2
\end{tabular} & $\begin{array}{l}\infty \\
0 \\
0\end{array}$ & 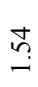 & 12.98 \\
\hline & 1000 & 9.9 & $8 \sigma^{\circ}+$ & $\dot{\circ} m$ & t. & $\dot{\infty} a$ & $\stackrel{t}{a}-$ & 约 & 13.42 \\
\hline
\end{tabular}


If the shielded cable and metal pipe are used in CL construction, the level of overvoltage from the side of the substation control house is close to permitted 4-6 kV with moderate and low soil conductivity. However, as the front of the lightning current pulse decreases, the level of overvoltage increases (Fig. 2). In conditions of low soil resistivity, considering equipment insulation strength margin, studied network is reliable to lightning overvoltage. In other conditions, application of SPD is justified.

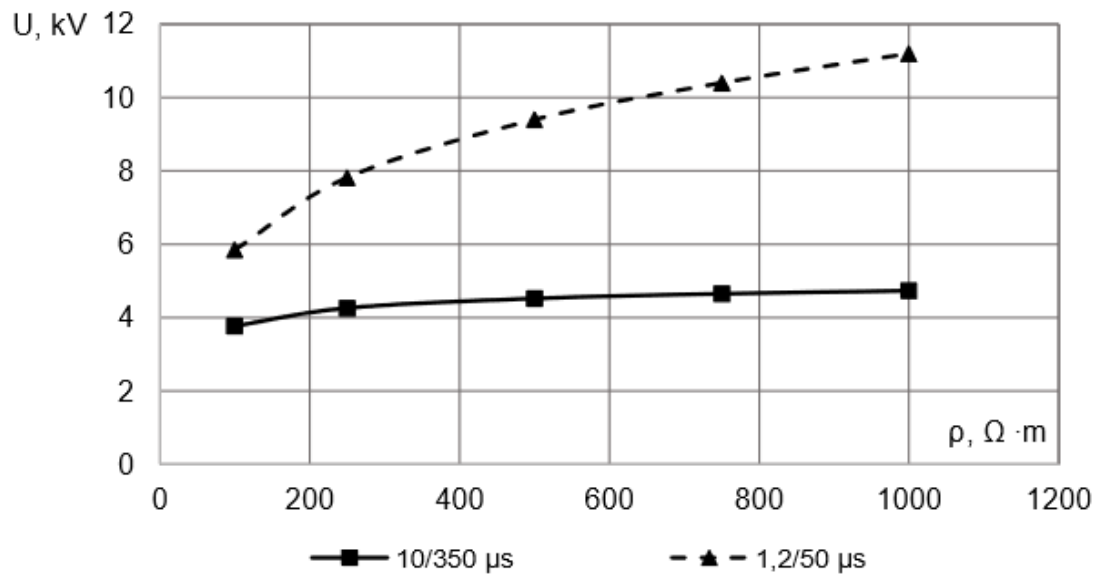

Fig. 2. Overvoltage in CL of illumination system with different waveforms of current pulse, when using a shielded cable and a metal pipe.

Recommended for illumination system of air insulated substation SPDs installation scheme is shown in Fig. 4. Due to the overvoltage growths when currents flow in the ED, SPDs have to be installed according to the L-PE, N-PE scheme (Fig. 3) to provide common-mode interference protection.

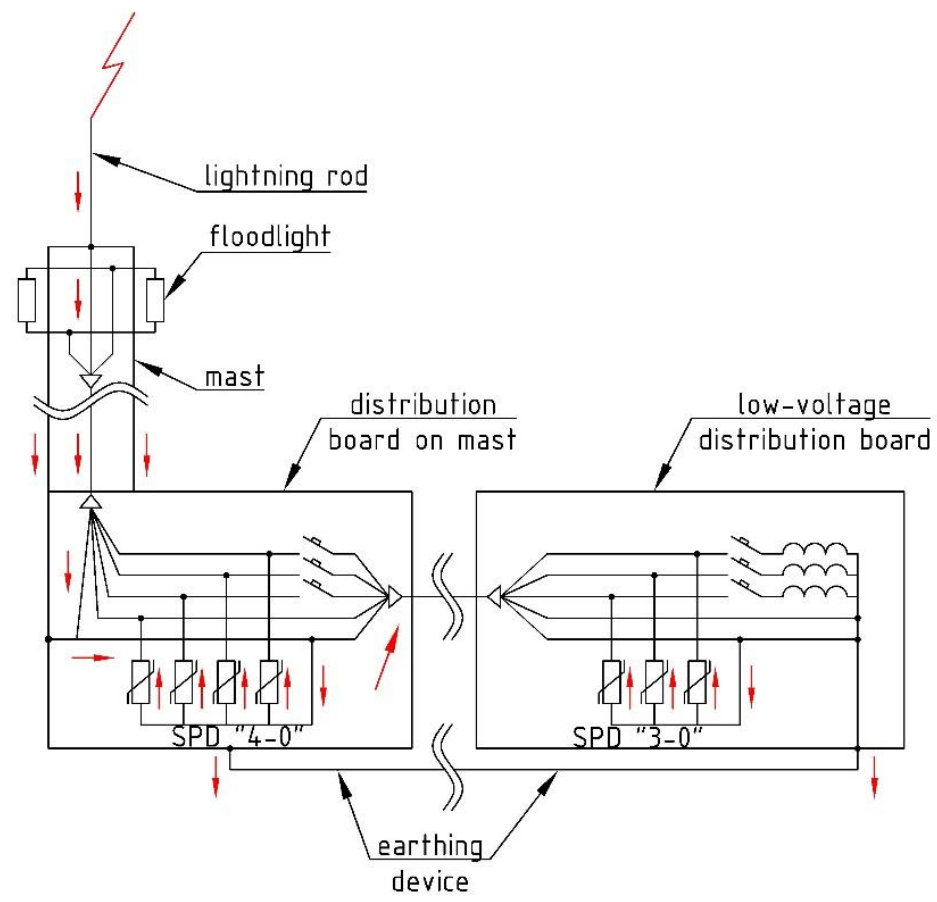

Fig. 3. SPDs installation scheme. 
It has to be noted, that interference transmission gain value (ratio of overvoltage amplitude on floodlight mast to overvoltage in substation control house) is less than minimum value 10 defined in [1]. So, according to calculation results, the impulse attenuation is slower. Overvoltage from floodlight mast direction rises with an increase in the length of the CL. The reason is neutral wire's grounding point moving away from the grounding area of the floodlight mast. Thus, necessity of SPD appliance in illumination system of air insulated substation is reasonable.

Computation results of current values in conductors of CL divided on two sections: from floodlight to distribution board on mast and from mast to substation control house, are summarized in Table 2. Not shielded cable without metal pipe was studied in order to determine the maximum value of the current flowing through the SPD. For the short CL the impact of the current impulse front on the current value in the CL also was studied.

Table 2. Current values in CL conductors for different cable length.

\begin{tabular}{|c|c|c|c|c|c|c|c|c|}
\hline \multirow{7}{*}{$\begin{array}{c}\text { Soil } \\
\text { resistivity } \\
\rho, \Omega \cdot \mathrm{m}\end{array}$} & \multicolumn{8}{|c|}{ Distance from mast to illumination control system, $\mathrm{m}$} \\
\hline & \multicolumn{6}{|c|}{50} & \multicolumn{2}{|c|}{220} \\
\hline & \multicolumn{8}{|c|}{ Current impulse, $\mu \mathrm{s}$} \\
\hline & \multicolumn{4}{|c|}{$10 / 350$} & \multicolumn{2}{|c|}{$1.2 / 50$} & \multicolumn{2}{|c|}{$10 / 350$} \\
\hline & \multicolumn{2}{|c|}{$\begin{array}{l}\text { CL without shield in } \\
\text { pipe }\end{array}$} & \multicolumn{2}{|c|}{$\begin{array}{l}\text { Absence of pipe } \\
\text { and shield }\end{array}$} & \multicolumn{4}{|c|}{ Absence of pipe and shield } \\
\hline & \multicolumn{8}{|c|}{ Current, A } \\
\hline & $\begin{array}{c}\text { По } \\
\text { мачте }\end{array}$ & From mast $\left.{ }^{2}\right)$ & $\begin{array}{c}\text { По } \\
\text { мачте }\end{array}$ & $\begin{array}{l}\text { From } \\
\text { mast }\end{array}$ & $\begin{array}{l}\text { По } \\
\text { мачте }\end{array}$ & $\begin{array}{l}\text { From } \\
\text { mast }\end{array}$ & $\begin{array}{c}\text { По } \\
\text { мачте }\end{array}$ & $\begin{array}{l}\text { From } \\
\text { mast }\end{array}$ \\
\hline 100 & 190 & 956 & 1153 & 4500 & 1278 & 3528 & 971 & 1083 \\
\hline 250 & 200 & 1045 & 1184 & 4739 & 1335 & 4613 & 982 & 1196 \\
\hline 500 & 210 & 1089 & 1198 & 5191 & 1383 & 5156 & 991 & 1322 \\
\hline 750 & 214 & 1100 & 1203 & 5225 & 1406 & 5415 & 994 & 1373 \\
\hline 1000 & 214 & 1091 & 1227 & 5300 & 1418 & 5589 & 997 & 1402 \\
\hline
\end{tabular}

Note: ${ }^{1}$ Current in CL section from floodlight to distribution board on mast - computed current value flowing in one conductor of CL section from floodlight to distribution board on mast; ${ }^{2}$ Current in CL section from distribution board on mast to the illumination control system in substation control house - computed current value flowing in one conductor of CL section from distribution board on mast to the illumination control system in substation control house. 


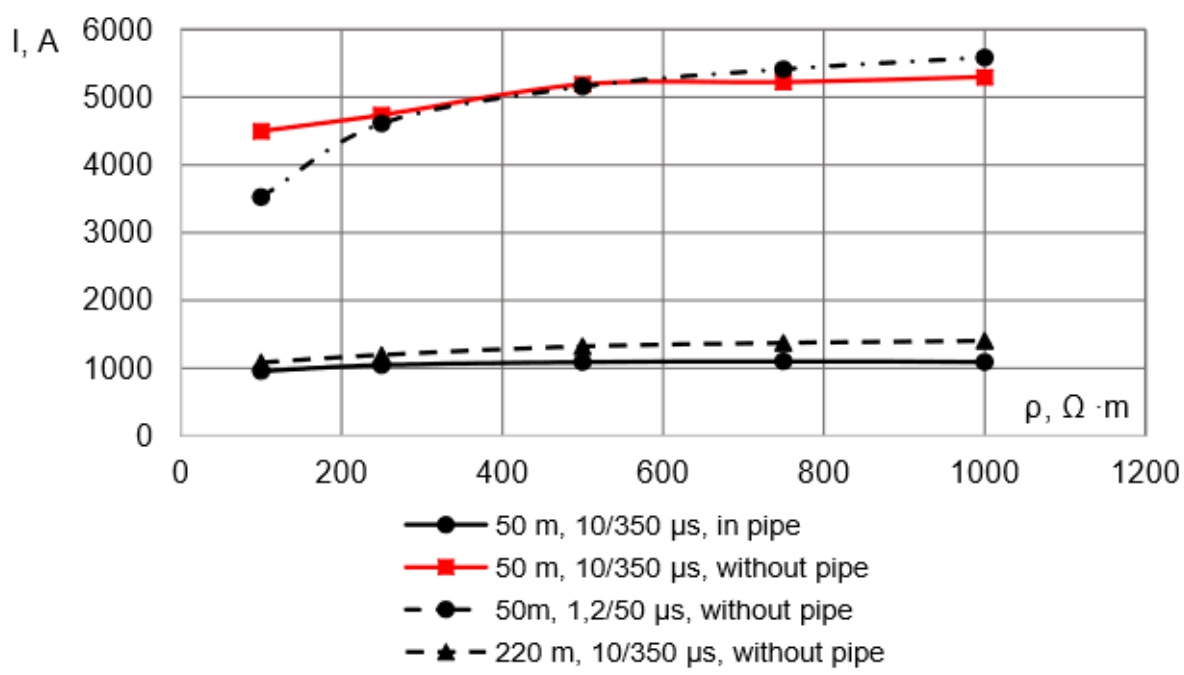

Fig. 4. Dependence of current value in CL conductors on soil resistivity for different current impulses and laying conditions.

\section{Experimental study results}

Experimental study results obtained in training ground PJSC «Lenenergo». In training ground territory placed open switchgears $110,35,10 \mathrm{kV}$, buildings and complete transformer substations. The voltage unavailability in high voltage network allows conducting experiments.

Unfortunately, there are some differences between the illumination system of the training ground and the real substation conditions. First of all, floodlight masts located far from the open switchgear and horizontal grounding network has a big step (up to $20 \mathrm{~m}$ ) near the masts. Secondly, the illumination control board placed in security building (illumination is mainly used as security lighting). CL not shielded and the metal pipe was not used for cable laying. In described conditions we expected that the measured partial current, flowing into the cable conductors during experiment, should be much higher than in the functioning substation.

Floodlight masts are powered in series, that is, two three-phase CLs outgoing from the mast. Thus, the number of CL conductors is 10 . According to design documentation CL length in one direction from the mast is $160 \mathrm{~m}$ and in another - $200 \mathrm{~m}$ (real lengths have to be shorter). The measurement scheme is shown in Fig. 5. Voltage was measured on generator circuit shunts and CL with Fluke 190-504 oscilloscope. 


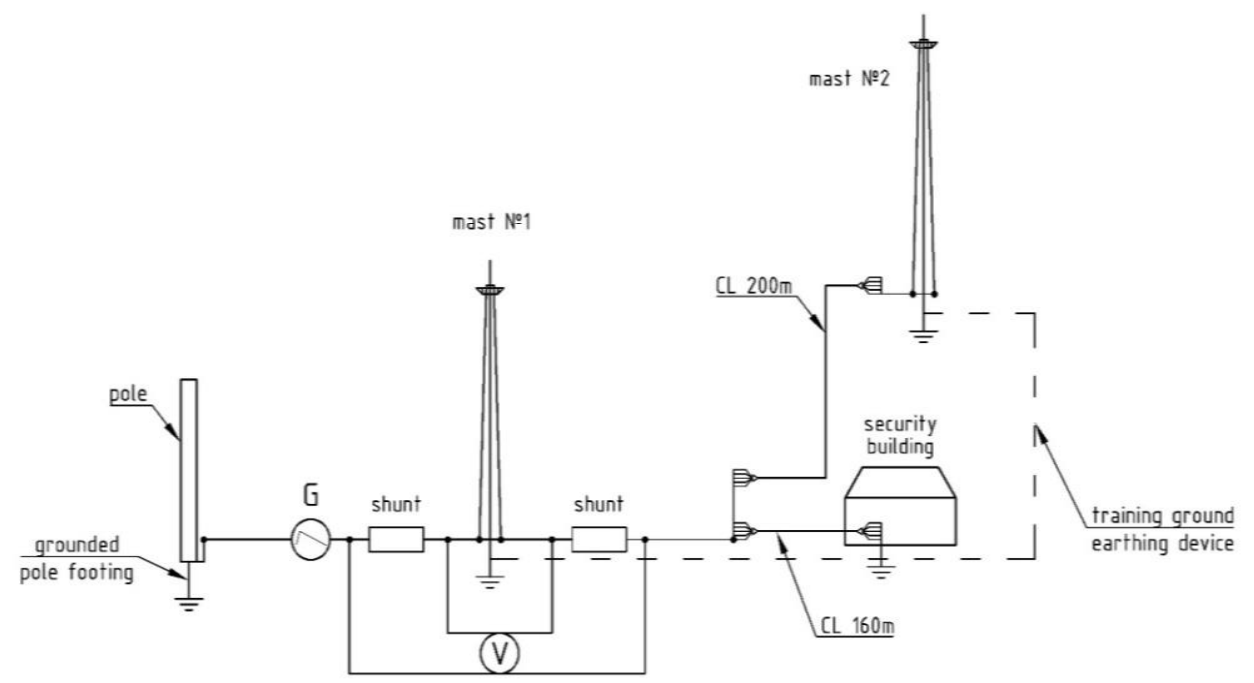

Fig. 5. Measurement scheme in training ground.

At the day of the measurement, the soil was frozen and the upper layer had a resistivity $1200 \Omega \cdot \mathrm{m}$. A voltage impulse of $1.2 / 50 \mu$ s and an aperiodic current of $8 / 20 \mu$ s with an amplitude 9 A was applied to the floodlight mast, the phase and neutral conductors were grounded on both sides of CLs in the illumination control board placed in security building and on another floodlight mast. The second output of the generator was grounded to the footing of the pole also placed in training ground but not connected to the ED. The voltage ratio made it possible to estimate the part of current flowing in CL. The oscillogram of voltage on the shunts of the generator and CL is shown in Fig. 6.

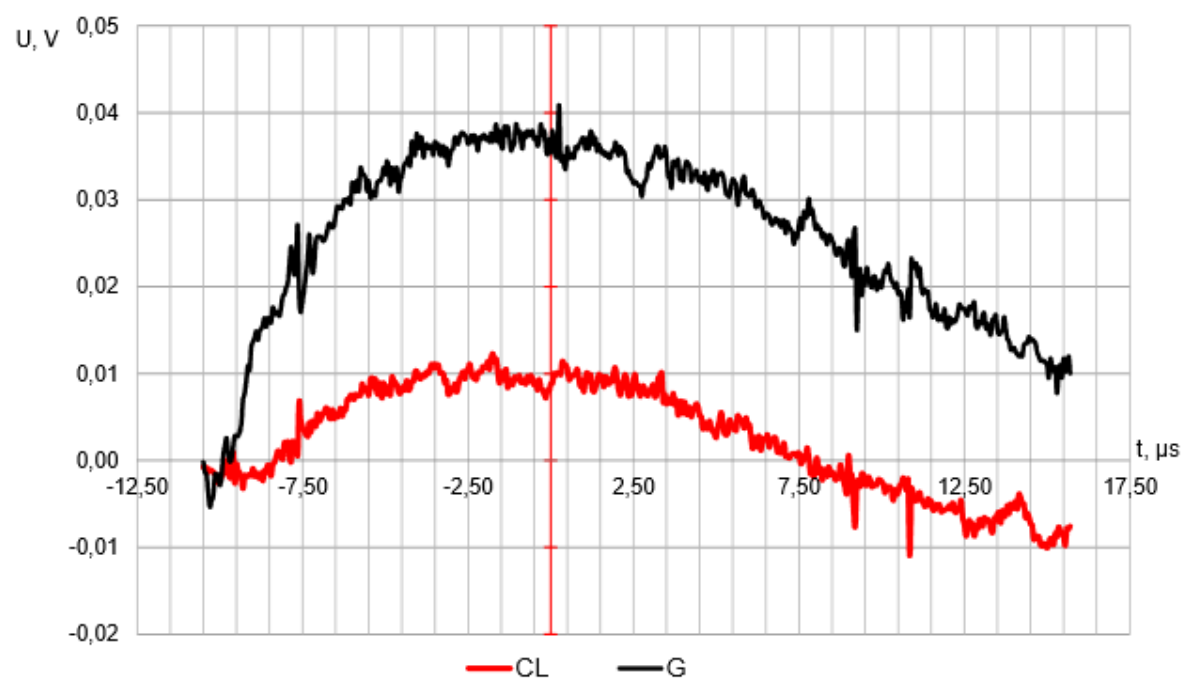

Fig. 6. Voltage at generator and cable shunts.

Voltage amplitude on the shunt of the CL is approximately $33 \%$ of the voltage amplitude at the shunt between the generator and the mast. If the lightning current impulse had amplitude of $100 \mathrm{kA}$, then a current impulse with amplitude of about $3.5 \mathrm{kA}$ would flow through each of the $\mathrm{CL}$ conductors. Considering the real illumination network 
parameters and if an SPD installed the amplitude of the current impulse in PE and N conductors would be slightly higher.

According to data from Table 2 value of current flowing in one conductor of CL section from distribution board on mast to the illumination control system in substation control house for CL length $220 \mathrm{~m}$ and soil resistivity $1000 \Omega \cdot \mathrm{m}$ is $1402 \mathrm{~A}$. Then in the training ground conditions (two five-conductor CL with length $360 \mathrm{~m}$ and soil resistivity $1200 \Omega$ $\cdot \mathrm{m})$ approximate evaluation of the part of lightning current $10 / 350 \mu$ s impulse can be found from the equation:

$$
\delta=\frac{I_{C L}}{I_{s t}}=\frac{1}{I_{s t}} \sum_{i=1}^{n}\left(\frac{N-L_{E}-I_{E}}{l_{m}}\right),
$$

where: $n$ - number of CLs, $N$ - number of CL conductors; $L_{c}-$ CL length from calculation model; $l_{m}-$ CL length in training ground; $I_{C L}-$ current flowing in CL (sum of currents in all CL conductors); $I_{s t}$ - standardized value of the lightning current impulse amplitude $(100 \mathrm{kA}) ; I_{c}$ - calculated current value in CL conductor CL length $L_{c}(1402 \mathrm{~A})$.

The expected part of the current flowing in all the conductors of two studied in training ground CLs is $17.5 \%$ of the calculated current amplitude. In the training ground conditions part of the current flowing from the mast to CLs have to be higher than in a real substation, due to ED and masts footing design features.

The obtained values of the currents in the CL conductors are significantly lower than the impulse discharge current of SPDs installed in substation. It can be explained by the following circumstance:

1. selection of SPDs parameters based on unreasonable methods or the absence of any methods in the presence of biased recommendations of the manufacturers of SPDs;

2.the design characteristic of the substation such as developed grounding network due to which a significant part of the lightning current is redirected to the ground is not considered;

3. the impact of cable length and cable lying conditions are not considered.

As a result, even in the $110 \mathrm{kV}$ substations conditions, in case of cable laying without pipe and simplifying the ED design, the use of an SPD with an impulse discharge current parameter higher than $10 \mathrm{kA}$ is inappropriate. At substations of a higher voltage class the length of the CL of the lighting network increases significantly. Thus, the conclusion made about the necessity and sufficiency of using SPDs with impulse discharge current parameter lower than $10 \mathrm{kA}$, is also relevant for substations of a higher voltage class.

\section{Conclusions}

In illumination system of air insulated substation application of SPDs for lightning protection is justified. The substation is characterized by developed grounding network and this is the one of the decisive features in the SPD parameters selection.

SPD parameters selection methodology for low-voltage substation networks protection, based on "estimated calculations" of lightning current part in the CL conductors, should be reviewed, since its use can lead to unjustified costs.

Recommended value of SPD impulse discharge current parameter for appliance in in illumination system of $110 \mathrm{kV}$ air insulated substation is $10 \mathrm{kA}$ or lower.

\section{References}

1. International Electrotechnical Commission, IEC 62305-1 - Lightning protection - Part 1: General principles (2010) 
2. G. B. Lo Piparo, T. Kisielewicz, C. Mazzetti, A. Rousseau, Electric Power Systems Research 146, 321-330 (2017) doi:10.1016/j.epsr.2017.01.038

3. J. He, Z. Yuan, S. Wang, J. Hu, S. Chen, R. Zeng, IEEE Trans. Power Deliv 25 (1), $187-195(2010)$

4. T. Kisielewicz, G. B. Lo Piparo, C. Mazzetti, 2017 IEEE International Conference on Environment and Electrical Engineering and 2017 IEEE Industrial and Commercial Power Systems Europe (I\&CPS Europe, 2017) doi:10.1109/eeeic.2017.7977651

5. G. B. Lo Piparo, T. Kisielewicz, et al., International Journal of Electrical Power \& Energy Systems 75, 38-49 (2016) doi:10.1016/j.ijepes.2015.08.022

6. V. Radulović, S. Mujović, SN Applied Sciences 1 (1) (2018) doi:10.1007/s42452-0180003-1

7. IEC Std. 61643-11, LV surge protective devices -Part 11: surge protective devices connected to LV systems - Requirements and tests" (2011)

8. IEC Std. 61643-12, LV surge protective devices-part 12: surge protective devices connected to LV power distribution systems - selection and application principles (2012)

9. CIGRE Technical Brocure 549, Lightning Parameters for Engineering Applications, WG C4.407, 117 (2013)

10. Y. Baba, V. A. Rakov, IEEE Transactions on Electromagnetic Compatibility, 56 (6), 1506-1521, 2014)

11. CIGRE Technical Brochure, Guideline for numerical electromagnetic analysis method and its application to surge phenomena, WG C4.501, 106 (2013)

12. R. Xiong, B. Chen, Y.-F. Mao, et al., IEEE Trans. Antennas Wireless Propag. Lett. 11, 957-960 (2012)

13. N. V. Korovkin, O. V. Frolov, et al., Electromagnetic Compatibility (EMC EUROPE), International Symposium, 1-5 (2012) doi:10.1109/emceurope.2012.6396752

14. S.L. Shishigin, D.S. Shishigin, N. V. Korovkin, 9IEEE International Symposium on Electromagnetic Compatibility, 834-838 (2015)

15. D. S. Shishigin, S. L. Shishigin, IEEE International Conference on Environment and Electrical Engineering and 2017 IEEE Industrial and Commercial Power Systems Europe (I\&CPS Europe, 2017) doi:10.1109/eeeic.2017.7977476 